\title{
A FACE ALEGÓRICA DA HISTÓRIA EM PEREGRINAÇÃO DE BARNABÉ DAS ÍNDIAS, DE MÁRIO CLÁUDIO
}

Maria Cecilia Rogers Paranbos ${ }^{1}$

RESUMO: O presente estudo pretende evidenciar em Peregrinação de Barnabé das Índias (1998), do escritor português Mário Cláudio, a presença de uma narrativa que constrói alegoricamente a primeira viagem marítima dos portugueses às Índias sob a liderança de Vasco da Gama. Nesta construção, será revelada uma nova face para a História, delineada em suas ruínas e, para a compreensão desse ponto de vista, serão trazidos os conceitos de alegoria e história, como o Barroco os concebeu, à luz dos estudos de Walter Benjamin em Origem do drama barroco alemão (1984).

PALAVRAS-CHAVE: Literatura Portuguesa contemporânea, Mário Cláudio, alegoria, história, barroco.

\section{THE ALEGORIC FACE OF HISTORY IN PEREGRINAÇÃO DE BARNABÉ DAS ÍNDIAS, BY MÁRIO CLÁUDIO}

\begin{abstract}
The present study intends to evidence in Peregrinação de Barnabé das Índias (1998), from the portuguese writer Mário Cláudio, the presence of a narrative that constructs an allegory of the first maritime's journey of the portugueses to the Índias, commanded by Vasco da Gama. In this construction, it will be revealed a new face to the History, designed in its ruins and, for the comprehension of this point of view, it will be brought the concepts of allegory and history, as the Baroque conceived them, conducted by the studies of Walter Benjamin in Origem do drama barroco alemão (1984).
\end{abstract}

KEYWORDS: Contemporary Portuguese Literature, Mário Cláudio, allegory, history, baroque.

\footnotetext{
${ }^{1}$ Mestre em Estudos de Literatura, área de conhecimento em Literatura Portuguesa e Literaturas Africanas de Língua Portuguesa pela Universidade Federal Fluminense. Dissertação defendida em 31/08/2012.
} 


\section{INTRODUÇÃO}

Em mais uma releitura de fatos históricos, Mário Cláudio romanceia em Peregrinação de Barnabé das Índias (1998) a primeira viagem dos portugueses às Índias, sob a liderança de Vasco da Gama. Nesta ficção, no entanto, não será o tom glorioso da conquista que irradiará da narrativa, mas o tom lutuoso do olhar contemporâneo que, transformando em ruínas a totalidade histórica, permitirá dar-lhe um novo significado, numa importante abordagem dialética que possibilita ao sujeito desvendar a face oculta dos diferentes momentos históricos para uma melhor compreensão do presente.

Para isso, o escritor fará embarcar nessa peregrinação o grumete Barnabé, personagem marginal, um cristão-novo da pequena Ucanha, nas imediações do Lamego, que secretamente alimenta sua crença original judaica numa época de intensa perseguição aos credos não católicos em Portugal. Barnabé personificará as muitas reflexões sobre o medo, sobre a morte e sobre a viagem que verdadeiramente glorifica o homem:

porque terror mais vasto aprendera ele no semblante de Vasco da Gama, o que os tornava idênticos nesse plano onde de modo único as razões da fraternidade se exprimem. Da recôndita tibieza do guia da frota derivava Barnabé a inutilidade do temor, e afigurava-se-lhe a morte religião comum, e a urgência de a suprir aventura do ser (CLÁUDIO, 1998, p. 111).

A narrativa não-linear será fragmentada sob os olhares de Barnabé, de Vasco da Gama e de um terceiro narrador, onisciente, cabendo ao leitor desvendar seus lugares neste jogo de peregrinações, em que é fortíssima ainda a presença do discurso religioso, da culpa adâmica e das representações da morte. O tempo do romance descreverá um movimento elíptico - uma vez que a narrativa não possui um centro (ou narrador) único, e que se inicia no presente para percorrer o passado através desses diferentes narradores e das lembranças das personagens principais para, no fim dessa viagem caleidoscópica, retornar ao presente, que parece então "iluminar-se", como prenuncia o título do último capítulo, As Lužes. Através de uma estrutura em dez capítulos, somos conduzidos a um sentido outro para o grande momento histórico que marcou a mítica portuguesa. Cabe lembrar que a reconhecida obra de Camões, Os Lusíadas, exalta a mesma viagem marítima, o seu comandante Vasco da Gama e os corajosos nautas portugueses - sem também deixar de tecer críticas aos ambiciosos do poder -, e que apresenta igualmente uma estrutura em dez cantos. Todo o romance estabelece um claro diálogo intertextual com a grande epopeia camoniana nos quinhentos anos decorridos da descoberta do caminho marítimo para as Índias, sinalizando para uma necessária releitura do passado português na construção de um novo presente - que decadente precisa rever-se.

Neste ponto, porque julgo ser interessante para este estudo, destaco Severo Sarduy, ao ser comentado no prefácio de seu livro Barroco (1989), por José Manuel de Vasconcelos que, referindo-se à escrita de tendência neobarroca do escritor cubano, revela que, para Sarduy, a "escrita é uma prática de artificialização", ou melhor, "cada escrita contém outra, comenta-a, 'carnavaliza-a', torna-se o seu duplo pintalgado; a página, enxertada de diferentes texturas, de múltiplos extratos linguísticos, tornou-se espaço de um diálogo: 
como um teatro em que os atores fossem os textos." (VASCONCELOS in SARDUY, 1989, p. 8). De maneira similar, é perceptível em Peregrinação de Barnabé das Índias a presença de um jogo narrativo, de um "duplo pintalgado", de um espetáculo lutuoso que dialoga com a obra camoniana e com o fato histórico propriamente dito.

Para a compreensão deste ponto de vista, tomou-se a leitura de Origem do drama barroco alemão (1984), de Walter Benjamin, no que se refere ao seu conceito de alegoria. Para Benjamin, "o alegorista diz a morte e quer significar a história, como o Barroco a concebia. Pois ao contrário do símbolo, que vê a história na perspectiva transfiguradora da redenção, a alegoria mostra ao observador a facies hippocratica da história como proto-paisagem petrificada." (ROUANET in BENJAMIN, 1984, p. 39). Acrescenta que a morte é o princípio estruturador da alegoria, pois para que um objeto ganhe significação alegórica, ele precisa ser arrancado de seu contexto, esvaziar-se, morrer. A caveira é então o objeto que melhor significa a existência humana, sujeita à catástrofe da natureza como destino, da mesma forma que "a ruína é o fragmento morto" (ibidem), ou seja, aquilo que restou da vida em sua efemeridade, e que estrutura o delineamento da face alegórica da história.

\section{Mário Cláudio: como o alegorista benjaminiano}

No Barroco, o homem deixa de perceber a História como um processo inscrito na história da salvação humana pela certeza de uma vida eterna, tal como era concebido na Idade Média. No Cosmos, o espaço ordenado renascentista não tem mais um centro único e as linhas orbitais dos planetas não transcrevem mais os círculos perfeitos de Galileu, alongando-se nas elipses keplerianas. Assim como das diferentes visões cosmológicas surgiu uma tensão entre o círculo e a elipse, da mesma forma essa tensão se estendeu para a própria episteme de cada época, refletindo a "agonicidade" do homem diante da consciência da fugacidade da vida - "em que todas as coisas são móveis e passageiras." (MARAVALL, 1997, p. 292). A mutabilidade, mobilidade e inconstância das coisas geram insegurança e incerteza diante do mundo. A melancolia é fruto de uma desordem íntima face àquele momento de crise, resultado das sucessivas guerras, das pestes, da miséria, da fome e do conflito interior que se estabelece pela confrontação entre o elemento pagão renovado pelo Renascimento e o elemento cristão renovado pela Contrarreforma, e que implica na renovação da alegoria como forma de expressão dessa confrontação. O homem está sujeito a um destino que o aniquila e que o conduz incondicionalmente à morte.

A alegoria, construída pelas ruínas e pelos fragmentos de um mundo "esquartejado", expôs a transitoriedade da história, que passou a estar presente apenas como ruína. Sobre isso, discorre Benjamin:

Como ruína, a história se fundiu sensorialmente com o cenário. Sob essa forma, a história não constitui um processo de vida eterna, mas de inevitável declínio. Com isso, a alegoria reconhece estar além do belo. As alegorias são no reino dos pensamentos o que são as ruínas no reino das coisas. Daí o culto barroco das ruínas (BENJAMIN, 1984, p. 200).

As fachadas partidas e as colunas despedaçadas dos monumentos legados da Antiguidade são, na visão moderna, apenas escombros do que sobreviveu às forças de 
destruição, sejam elas naturais ou não. Entretanto, é o fragmento significativo - ou aquilo que jaz em ruínas - o elemento fundamental da criação barroca. O poeta barroco cria um "todo" a partir de ruínas, que na obra de Calderón "aparece como uma parede de alvenaria, num prédio que perdeu o reboco." (BENJAMIN, 1984, p. 201). Assim também, a natureza, por sua efemeridade, imprime a imagem do fluxo histórico como natureza decaída. Ao se pensar no objeto alegórico, de acordo com o pensamento de Benjamin, temos que, pelo olhar melancólico, esse objeto jaz como se estivesse morto, e só dispõe da significação que lhe é atribuída pelo alegorista: "Em suas mãos, a coisa se transforma em algo de diferente, através da coisa, o alegorista fala de algo diferente, ela se converte na chave de um saber oculto, e como emblema desse saber ele a venera." (ibidem, p. 206).

O século da escritura do romance de Mário Cláudio é o século XX. Por que então as similitudes com a forma de expressão barroca? Em seu estudo sobre o Barroco, Affonso Ávila aponta que ela decorre das aproximações entre "dois instantes da civilização ocidental que colocam em crise os mesmos valores, dois homens que experimentam com isso uma análoga perplexidade existencial, duas artes que repercutem em sua linguagem uma bem parecida pressão de historicidade" (1980, p. 11). Lembremos que o olhar contemporâneo está encoberto pelas ruínas das grandes guerras mundiais, pelas ruínas das crescentes catástrofes naturais, e pela melancolia do fim de um verdadeiro socialismo. Além disso, "somos os sobreviventes de uma destruição paulatina de todos os grandes valores antigos, que foram aviltados e transformados em escombros pela mercantilização da vida" (KONDER, 1999, p. 36), ou como bem ressalta Sérgio Paulo Rouanet na apresentação introdutória de Origem do drama barroco alemão: "Que arbitrariedade é essa, que reflete nossa própria experiência? O tirano e o mártir vivem entre nós. Diariamente assistimos a execuções e massacres. O luto é nosso elemento. O Barroco está em nós e nós nele." (ROUANET in BENJAMIN, 1984, p. 47).

Diz ainda Benjamin que um dos temas mais fortes da alegoria se relaciona à visão da transitoriedade das coisas e "se instala mais duravelmente onde o efêmero e o eterno coexistem mais intimamente.” (BENJAMIN, 1984, pp. 246-247). Por isso, a constância no Barroco dos temas alegóricos ligados à morte e à história como ruína. Construindo em seu romance uma fisionomia alegórica para a primeira viagem de descoberta do caminho marítimo para as Índias, e para isso lançando mão de temas da representação da morte, Mário Cláudio se aproxima do artista barroco e de sua concepção alegórica, de acordo com Benjamin, apontando para uma revisão do passado e da identidade de Portugal.

Dono de um conhecimento superior, o "alegorista" de Peregrinação de Barnabé das Índias não se exime em despistar-nos com dados históricos verídicos amarrados com datas, nomes e locais que marcaram os acontecimentos oficialmente relatados. Entretanto, sua intenção sugere a construção de uma nova fisionomia para a história, através da exposição de suas ruínas, reveladas pela remoção do "reboco" de uma parede aparentemente harmônica e sublime. É o que parece delinear o narrador quando, pelo olhar do pobre rapazote Barnabé, critica a opressão imposta aos judeus pelo "valeroso e insigne" Rei D. João II:

Num dos últimos dias de Outubro de mil quatrocentos e noventa e cinco espalhou-se a nova da morte daquele valeroso e insigne Rei Dom João 
II. [...] Não o choravam as mães dos meninos judeus que à força mandara o soberano horrendamente acondicionar em umas quantas barcas, e despejar na ilha de São Tomé, indefesos ante o sofrimento do ânimo e a fúria dos elementos (CLÁUDIO, 1998, pp. 86-87).

$\mathrm{Na}$ esteira da construção alegórica, mais uma vez será dessacralizada a figura real neste caso D. Manuel -, quando da partida das naus para a grande viagem marítima, e que mostra Barnabé imaginando o que segreda o "risível gabarola que ambicionava o império do Mundo": "Que se internem por esse oceano, e que se não atrevam a regressar de porões sem o que importa, e se houverem de perecer, que morram antes de nós, já que nos brindou o Omnipotente com fumos de eternidade.” (CLÁUDIO, 1998, p. 118), revelando sua indiferença mascarada para com os corajosos navegantes.

Em suas muitas reflexões, o jovem grumete traduz um pensamento maduro que evidencia a falsidade das verdades cristalizadas pelo Rei e pela Igreja, como se percebe na passagem em que argumenta consigo mesmo o nosso herói sobre a mensagem imbuída do discurso religioso católico do respeitado comandante Paulo da Gama, logo no dia seguinte à largada das naus: "e nem via porque demasiado diverso fosse este catecismo daquele em que me tinham criado os meus paizinhos" (ibidem), trazendo o questionamento sobre um Portugal, dominantemente católico, que marginalizou e perseguiu os portugueses de diferentes credos. Isto se reforça no seguinte trecho que relata a boa impressão dos nautas portugueses sobre as mesquitas encontradas na Ilha de Santiago, em mais um fragmento significativo de esvaziamento da primazia católica:

Acrescentavam que mui formosas se manifestavam na sua maioria, e nada escuras como as igrejas dos cristãos, mas abertas à claridade como se locais de recreio e de alegria fossem elas, que não de padecimento e de paixão. E partilhando aquela terra adeptos de variadas religiões, maravilhoso se revelava que não entrassem em confronto, e entre si se tolerassem como herdeiros que descendessem, e sem dúvida que descendiam, da única e amorável entidade que os tinha criado. E pensava Barnabé em seu foro interior que de idêntico modo se deveriam comportar os que obedeciam ao Papa (CLÁUDIO, 1998, p. 184).

Nesta peregrinação será a personagem marginal aquela capaz de superar o medo da morte, superando, inclusive, a própria morte, como profetizado pelo influente judeu Joseph, padrinho de Barnabé e possuidor de um saber entre científico e místico: "haverás de copiar os nossos que se libertaram do cativeiro do Egipto, e como eles, e para além do medo, e sem que a morte te assuste, intacto atravessarás as soerguidas vagas da imensidão dos mares." (CLÁUDIO, 1998, p. 80), o que de fato acontecerá, ao ser salvo da morte, mais de uma vez, por um anjo de nome Rafael - coincidentemente o mesmo nome da nau que tripulava -, numa transcendência que eleva Barnabé a um estágio e conhecimento superiores, e que nos remete ao conhecimento da "máquina do mundo" dado à Vasco da Gama pela Deusa Tethys no episódio da Ilha dos Amores n'Os Lusíadas, estabelecendo um diálogo sinalizador de que a verdadeira glória de um homem está na conquista de si:

E voavam a par, marinheiro e arcanjo, reunidos na máquina que o Espírito sustém, e desgrenhavam-se no azul os cabelos de ambos, e um luzeiro se lhes incrustara nas órbitas, e em sua esteira de centelhas 
flutuavam os que pelo Planeta tinham vagueado desde o princípio do Mundo, e na unidade se congregavam, e nem lhes pertencia o rosto, porquanto lhes retirara Rafael a máscara que os corrompera (CLÁUDIO, 1998, p. 200).

O mesmo não alcança o altivo comandante Vasco da Gama, que perseguido pelo medo e pelos espectros da morte, é desnudado pelo alegorista, quando revela a frágil face humana do capitão, lançando as pistas de um conhecimento oculto, que transforma o narrador no "senhor das significações" de Benjamin. Logo no início da narrativa, estranhamos a personagem ser descrita como um velho calado e com frio em seu "capote de castorina, puído nos lugares do atrito dos gestos, salpicado pelos oceanos que imaginar" (CLÁUDIO, 1998, p. 13). Este parece ser mais um indício da elaboração alegórica, como se estivesse sendo feito um convite para participarmos de um jogo de desvendamentos, que insinua: quem é esse pobre velho melancólico? Dele, todavia, somente o narrador/alegorista tem o conhecimento supremo:

Um velho no Inverno é isto que conto, e vai-se tecendo o livro com a sua figura, porque de surpresa entardece para o que arduamente respira, e sofre da maldição de persistir sem serventia, e se chama aquilo que lhe chamarmos, quando não o houver baptizado a história com o nome que o distinga (CLÁUDIO, 1998, pp. 13-4).

Entretanto, ainda como parte dessa proposição lúdica, ao velho Vasco será permitida a compreensão do sentido essencial da viagem de descobertas, quando, reconhece no velho andarilho Barnabé, que lhe bate à porta muitos anos após a grande viagem, o seu verdadeiro herói: "Deus te abençoe, meu rapaz, que foste tu, foste tu, e mais ninguém, quem essas Índias na verdade descobriu." (CLÁUDIO, 1998, p. 278). Neste momento, personagem e história serão "iluminados" pelo alegorista e as cordas da narrativa unirão Vasco da Gama e Barnabé, assim como unirão os vultos míticos e os portugueses que foram excluídos do reconhecimento histórico, permitindo, enfim, revelar uma nova face para a história, delineada em suas ruínas: "Uma ubíqua névoa os envolveu, formada pelas volutas da poeira, quando não pelos desacertos da alma, e nela cabiam ambos, comandante e grumete, pela experiência puídos, tão desprezados de tudo como se os caminhos do mar não houvessem divisado" (CLÁUDIO, 1998, p. 277).

\section{Melancolia de Vasco da Gama}

No século XVII, a cultura barroca estava submetida a um poder absoluto, que era representado pelo Rei, que com sua autoridade poderia naturalizar a história, livrando o homem dos horrores da história-destino, como relata Rouanet sobre as conclusões de Benjamin: "a política absolutista é uma política de naturalização da história. A função do tirano é a restauração da ordem, durante o estado de exceção: uma ditadura cuja vocação utópica será sempre a de substituir as incertezas da história pelas leis de ferro da natureza." (ROUANET in BENJAMIN, 1984, p. 36). Paradoxalmente, o Príncipe do drama barroco é também "o paradigma do melancólico" (ibidem, p. 165), sendo ele criatura sujeita às 
mesmas fragilidades das demais criaturas. Benjamin destaca o importante comentário de Leo Armenius sobre os elementos básicos que caracterizam o melancólico Príncipe:

Ele treme diante de sua própria espada. Quando se senta à mesa, o vinho mesclado contido nos cristais se converte em fel e veneno. Assim que o dia termina, o negro rebanho, o exército do medo rasteja sorrateiramente, e vela em seu leito. Envolto em marfim, púrpura e escarlate, ele não pode nunca repousar tão serenamente como os mortos sepultados na dura terra. Se por acaso consegue adormecer por um curto período, Morfeu o agride, e transforma em negras imagens noturnas os seus pensamentos diurnos, apavorando-o ora com sangue, ora com destronamentos, ora com incêndios, ora com sofrimento e morte, ora com a perda de sua coroa. (...) onde está o cetro está o medo (BENJAMIN, 1984, p. 167).

Com essa leitura, reconhecemos no romance de Mário Cláudio as similitudes entre a personagem de Vasco da Gama, a quem é dado o poder do comando de uma difícil e importante expedição marítima, e a personagem do melancólico e torturado Príncipe do drama barroco. Como mártir, Vasco está sujeito ao sofrimento e hesita porque está na fronteira entre dois mundos, sendo criatura sujeita à natureza e soberano que precisa dominá-la - "o verdadeiro nome dessa hesitação é acedia, a sombria indolência da alma, traço mais geral da sintomatologia melancólica." (BENJAMIN, 1984, p. 30). Também Vasco é um líder assombrado pelo medo que, já na sua infância, surge na imagem de uma simples "alforreca", e que, na juventude, se transforma na poderosa hidra que o persegue por toda a vida, em pensamentos e delírios:

E na velhice de Évora é na terrífica hidra, exprimindo a fúria das cores que se intercadeiam, amarelo e negro e vermelho, que haverá de se transformar a alforreca da infância de Sines. Por uma confusão de línguas esvoaçantes e de presas arreganhadas se exterioriza a ira da besta, pintada na parede do claustrim, obedecendo àquilo que ordenou ele que se executasse, não tanto com vista a apregoar a sumptuosidade do seu estado como a exaurir um medo que não alcançou desfazer (CLÁUDIO, 1998, p. 21).

Quando no comando de sua esquadra, o jovem Vasco não deixava transparecer seus medos à tripulação, "aferrado à coragem que para si engendrara, apresentava-se-lhes o capitão na impassibilidade do semblante.” (CLÁUDIO, 1998, p. 22). No entanto, em meio aos terríveis tufões e às tempestades carregadas de raios que se engolfavam e que eram absorvidos pelas profundezas abissais, ele distinguia o dorso da besta (CLÁUDIO, 1998, p. 24), pois ocorre com o melancólico "no início o que ocorre com alguém que tenha sido mordido por um cão raivoso: tem sonhos terríveis, e temores sem razão." (BENJAMIN, 1984, p. 167). Assim, se por um lado demonstrava-se calmo e transmitia segurança aos seus subordinados, por outro, sentia-se dominado pelo terror que ia crescendo dentro de si na figura do bicho horrendo - "a hidra das sete cabeçorras do medo" - espelho de sua fragilidade de criatura:

A cada segundo de suas navegações a sentira presente e apta a surdir, ataviada dessa ramaria que medra nos abismos, voltando os focinhos todos em desconformes sentidos. E com os ferrões agudos atingiria o 
coração deste e daquele, e injetaria o veneno, e apropriar-se-ia da presa, metodicamente a devorando com um maquinal movimento das mandíbulas de afiadíssimos dentes. (...) Num furor insultava a marinhagem, e horrorizava-se diante da ideia de que o vissem tremer. [...] Traçava a rota a que obedeceriam, e duvidava de que não fosse ela de encontro ao mastodonte, e aspirava nos ventos o que pudesse palpitarlhe como um especialíssimo odor, a trapos chamuscados e a vapores sulfurosos, a vómito e a fezes e a quanto denunciasse a proximidade dos potentados do Inferno (CLÁUDIO, 1998, p. 37-38).

Nem as rezas aprendidas na infância conseguem diminuir o pânico que torce seus intestinos e o faz transpirar "na angústia da iminência da morte, e o amargor de que salvação nenhuma haverá de o ressarcir dos trabalhos que arrostou." (CLÁUDIO, 1998, p. 26). Cabe ressaltar a devoção religiosa do comandante, educado no rígido dogma do catolicismo - que estabelece a culpa adâmica e o castigo representado pelo Demônio. Aliás, a narrativa será percorrida pelo discurso religioso, delineador das oposições céu/inferno, anjos/demônios, pecado/salvação, em contrapontos que têm por objetivo realçar a coexistência dessa dualidade conflituosa como premissa da condição humana, e que também é marca da arte barroca. Quanto a isso, é interessante relembrar que no drama barroco, segundo a tese de Benjamin, a condição principesca do protagonista tem a intenção de ilustrar a fragilidade das criaturas - o que se torna mais visível naqueles de alta linhagem -, sendo a morte não um destino individual, mas de toda criatura humana. Ela representa a consciência diante de sua impotência e do seu desamparo. O drama barroco é movido pelo destino - onipotente -, e que submete a vida da criatura à ordem da natureza pela culpa. A melancolia é inerente ao homem que está sujeito a uma catástrofe que o aniquila, consumada pela história natural - cega e ameaçadora: "esvaziada de sua intencionalidade messiânica, a história é, com efeito, uma sucessão de catástrofes, que acabará culminando na catástrofe derradeira." (ROUANET in BENJAMIN, 1984, p. 35). Em suma, a morte constitui não somente o conteúdo da alegoria, como também o seu princípio estruturador e, portanto, ela está "no cerne da alegoria e no cerne da história." (ibidem, p. 40).

\section{Para uma escrita visual do alegórico}

A arte barroca procura dimensionar o espaço agônico entre a materialidade transitória das coisas e a transcendente perenidade do espírito "nas seis faces de um dado cujo lance é sempre o jogo consciente da forma, da cor, da palavra, da ideia, do ritmo, da melodia." (ÁVILA, 1980, p. 35). Assim como o grande mestre das palavras, Pe. Antonio Vieira, Mário Cláudio elabora o seu discurso "como uma série de lances sobre o tabuleiro de xadrez, onde as peças são movidas a um só gesto pela impulsão lúdica e o descortino lúcido do jogador." (ibidem, p. 65).

No Barroco, a palavra parece dobrar-se sobre si própria numa figura circular. Nele, temos a escrita visual do alegórico, cuja tensão fonética contida na sua linguagem conduz diretamente à música, impregnada de sentido (BENJAMIN, 1984, p. 232), e assim também, como o alegorista benjaminiano, Mário Cláudio emprega em seu romance uma linguagem 
predominantemente metafórica e imagética, em que as palavras encantam e seduzem pela cadência voluptuosa do som.

Através da ostentação, o Barroco buscava agir sobre as mentalidades, dirigindo-se predominantemente aos sentidos, para isso mobilizando todos os recursos da retórica. Daí o privilégio dado ao código visual, inclusive na literatura, pois "uma imagem é aquilo no qual o Pretérito encontra o Agora num relâmpago para formar uma constelação, (...) a imagem é dialética em suspensão."” A linguagem alegórica aparece assim "compondo por metáforas e claros-escuros o mundo em representação” (ÁVILA, 1980, p. 34).

Por outro lado, Benjamin discorre que "na esfera da intenção alegórica, a imagem é fragmento, ruína." (BENJAMIN, 1984, p. 198). Assim como nos procedimentos linguísticos do Barroco, em Peregrinação de Barnabé das Índias é marcante a construção alegórica pelas imagens, seja no relato das catástrofes naturais enfrentadas pelos nautas, seja nas reflexões ou visões fantásticas dos narradores, expressas pelo adensamento de uma escrita de vocabulário rebuscado, e composta ainda por longas frases muitas vezes com sintaxe de ordem indireta e longos parágrafos excessivos em seus detalhes descritivos, em que se destacam as intermináveis enumerações precedidas pela conjunção "e":

E quando penetrei na oficina surgiu-me assentado o meu primo Joseph, e de costas para mim, e debruçando-se para um cartulário, e ficara especado eu, a olhar como um néscio o rebuliço de escriturações, de restos de tigeladas de leite e de cousas de astrologia, esferas e lentes e compassos, e várias que ignorava como se chamariam, e finalmente virou-se ele, e sacudiu os braços como um pregador, e desatou na cegarrega que aí vai (CLÁUDIO, 1998, p. 78).

É marcante ainda a presença de um léxico repleto de preciosismos acrescido "de formas retiradas de sua linearidade e retensas num arco novo de recargamento estético pelas operações sistemáticas de ambiguidade." (ÁVILA, 1980, p. 58), como Ávila se refere ao Barroco. Esse encurvamento é realçado no romance pela sombra da melancolia, da morte na forma do cadáver em decomposição e da forte presença do discurso maniqueísta cristão, contrastes que não se realizam como disjunções, mas como co-presenças que coexistem.

O drama barroco pressupõe espectadores submergidos na iminência do movimento da história, ou seja, pressupõe seres humanos enlutados. Segundo Benjamin, "os espectros, como as alegorias profundamente significativas, são aparições que se manifestam no reino do luto. Elas são atraídas pelos lutuosos, pelos que ponderam sobre sinais e sobre o futuro.” (1984, p. 217), o que percebemos nos pesadelos e visões de Barnabé:

Carregava o espectro um pesadíssimo saco, e era como um penitente que ia ele progredindo, condenado à miséria de até à eternidade andar arrastando o lastro dos pecados que cometera. E ao dele se abeirar o pobre moço, voltava-se o encoberto com lentidão enorme, a descobrir o rosto roído pela lepra, e faltava-lhe um pedaço da face direita, e oferecia a alvura do maxilar. Retirava do alforje uma maçã, e estendia-a a Barnabé assombrado (CLÁUDIO, 1998, p. 60).

\footnotetext{
${ }^{2}$ Georges Didi-Huberman citando Benjamin em O que vemos, o que nos olha (1998, p.182).
} 
Na memória de Vasco da Gama as imagens das tempestades enfrentadas são também narradas com fortíssimos matizes. As descrições das catástrofes naturais se igualam à imagem da poderosa bidra que assombrava o comandante, em cenas que despertam os sentidos e se sobrepõem à razão, revelando ainda uma riqueza de detalhes que transformam a linguagem em manchas de pintura:

Mas significava isso que desembestara a borrasca, a qual ia explodindo com enorme fragor, e desconjuntavam-se os cascos num rangido de pregos que se desprendessem das tábuas, e lambiam os vagalhões o cavername das barcas, e eram zurridos e berros, estrépitos e assobios que se cruzavam. (...) E no centro da treva, tenso como o seio de uma rosa de obsidiana, principiara o comandante a divisar um dorso reptilíneo, a boiar numa zona de sereníssimas águas. Para quem em seu volume se firmasse avantajava-se o bruto numa sucessão de corcovas, desfocandose na nuvem de vapores e borrifos (CLÁUDIO, 1998, pp. 23-24)

Assim também acontece na composição das imagens repulsivas: da boca de Barnabé "se lhe enche um enxurro de pus" e "os dentes se despregam um a um das gengivas" e "cuspia a mistela arranhante da garganta, e cobria-se-lhe o peito de pústulas que até aos ossos lhe esburacavam a lassidão das carnes." (CLÁUDIO, 1998, p.169), numa referência às doenças que submetiam os marujos a terríveis sofrimentos. Se pensarmos na arte barroca, é possível perceber aqui a mesma forma que apela para os recursos da impressão sensorial e que pretende comunicá-la sob um grau de tensão tal que "transporte o receptor, o espectador, da simples esfera de plenitude intelectual e contemplativa para uma estesia mais franca e envolvente - mais do que isso, para um êxtase dos sentidos sugestionadamente acesos e livres." (ÁVILA, 1980, p. 20).

A descrição das cidades igualmente parece se delinear em pinceladas barrocas, correspondendo a uma escrita excessiva na pormenorização e nas metáforas, que remetem ao aglomerado das massas:

aparecia-me aquele lugar igual a um porto onde se houvessem sobreposto variegadas raças de humanos, nas suas ruelas se encontrando e se desencontrando, alçando-se uns certos aos esplendores que a fortuna lhes concedia, e declinando outros à poeira a que o fado mofino os condenava, e demasiadamente se comprimiam as gentes para que pudesse eu dilucidar os fios do tecido que se estendia, e atingia-me como que uma onda de cores desdobradas, e como que vendaval de multiplicadas vozes (CLÁUDIO, 1998, p. 214).

Ou refletem a degradação humana, quando Barnabé revela suas impressões sobre a doença venérea que o aflige, após seu envolvimento obsessivo com uma prostituta, como se a cidade e seus habitantes se contagiassem de suas chagas,

e que ia carcomendo o reboco dos prédios, e que se ramificava pelos carreiros onde a céu aberto fluíam os humilhantes líquidos da contingência dos homens. Um fedor de abominação ascendia das profundas dos armazéns, e invadia a Baixa, a impregnar o interior das casas, a saturar a roupagem dos habitantes, a agasalhá-los numa inconsútil capa de asquerosas imundícies (CLÁUDIO, 1998, p. 86). 
Encontramos, nesta narrativa, a presença de certo tom dominante, uma preocupação pelo pormenor, uma atenção com os odores, com os sons, um perambular sem fixação, que conduzem ao transbordamento das imagens. Além disso, de forma similar ao Barroco, no romance de Mário Cláudio também "o palco é móvel, peregrina, como a corte, de cidade em cidade, e nele se desdobra um espetáculo lutuoso, destinado a homens enlutados.” (BENJAMIN, 1984, p. 29).

\section{Considerações finais}

Apreende-se desse, assim como de outros romances de Mário Cláudio, “uma visão renovadora, em que os fatos do passado são relidos e recriados em função de uma necessidade crítica e de uma tentativa de compreensão do presente." (CALVÃO, 2008, p. 41), pensamento que busquei construir através da leitura de Benjamin sobre a alegoria barroca da história como ruína, que, como tal, permite a aquisição de novos significados, encobertos pelas aparências do texto, o que se aproxima de um procedimento próprio do Barroco e que permeia uma significativa parte da ficção contemporânea.

Pudemos perceber que a personagem Vasco da Gama se aproxima da representação do Príncipe do drama barroco, sendo ambos assombrados por visões aterradoras e dominados pelo medo - chegando até mesmo a momentos de loucura embora estejam em posições de comando absoluto. De maneira inversa, Barnabé, a personagem marginal, "com uma mancha de canalha de sua criação" (CLÁUDIO, 1998, p. 46), ascende no decorrer da narrativa - em um indício do verdadeiro significado dessa peregrinação.

Com temas caros ao Barroco, tais como a morte, a melancolia e o luto, Peregrinação de Barnabé das Índias é construída como uma refinada alegoria da história - entendida como Benjamin a concebeu em seu estudo sobre o drama barroco: "dizer uma coisa para significar outra". Aliás, como o título em alemão, Tranerspiel, revela em sua tradução - jogo e luto, também a narrativa de Mário Cláudio se delineia entremeada por estes dois elementos fundamentais. O luto permite ao alegorista "dizer a morte e significar a história" e o jogo, ou a encenação, possibilita ao narrador estabelecer com o leitor um pacto lúdico, importante para a construção alegórica e prenunciador de um novo percurso literário.

Iluminado pelo novo significado dessa viagem ao passado, o comandante Vasco da Gama decide enfrentar sua hidra, abandonando o inverno, a velhice, a decadência, indo ao encontro de um futuro, no qual, as glórias de Portugal serão para todos os portugueses que morreram na expedição, assim como os desconhecidos marujos Pêro Mendes, Leonardo, Fernão Gonçalves ou Martin Eanes, que surgem nas visões de Barnabé sob a forma de pombas - símbolos de paz e comunhão. Na verdade, Barnabé é o verdadeiro protagonista da peregrinação às Índias, como o título aponta ou como ele mesmo deduz : "definitivamente dobrara os cabos, e vencera os remoinhos, e contornara as monções de uma travessia interior" e "voltava da aventura com um tesouro que em riquezas de trato do comércio se não formulava, mas que nos medos resolvidos fora amassado." (CLÁUDIO, 1998, pp. 245-249). Da mesma maneira, as cordas da tessitura alegórica apontam para um 
Portugal que precisa perseguir as luzes de seu futuro, rememorando o passado e deixando para trás o frio das neves, seus demônios e suas chagas.

\section{REFERÊNCIAS BIBLIOGRÁFICAS}

ÁVILA, Affonso. O lúdico e as projeções do mundo barroco. São Paulo: Perspectiva, 1980.

BENJAMIN, Walter. Origem do drama barroco alemão. Tradução Sérgio Paulo Rouanet. São Paulo: Brasiliense, 1984.

CALVÃO, Dalva. Narrativa biográfica e outras artes: reflexões sobre escrita literária e criação estética na Trilogia da mão, Mário Cláudio. Niterói: Eduff, 2008.

Viagem e Morte em Peregrinação de Barnabé das Índias, de Mário Cláudio. O Marrare - Revista da Pós-Graduação em Literatura Portuguesa da UERJ. Disponível em: www.omarrare.uerj.br/numero9/dalva.html. Acesso em 20/12/2010.

CAMÕES, Luís de. Os Lusíadas. Lisboa: Porto Editora, $5^{a}$ edição, s/d.

CLÁUDIO, Mário. Peregrinação de Barnabé das Índias. Lisboa: Publicações Dom Quixote, 1997.

DIDI-HUBERMAN, George. O que vemos, o que nos olha. São Paulo: Editora 34, 1998 [1a. Reimpressão 2005].

KONDER, Leandro. Walter Benjamin: o marxismo da melancolia. Rio de Janeiro: Civilização Brasileira, 1999.

LA BARCA, Pedro Calderón de. A vida é sonbo. Tradução de Renata Pallottini (Org). Editora hedra, 2007.

MARAVALL, José Antonio. A cultura do barroco: análise de uma estrutura histórica. Tradução Silvana Garcia. São Paulo: EDUSP, 1997.

SARDUY, Severo. Barroco. Tradução Maria de Lurdes Júdice e José Manuel de Vasconcelos. Lisboa: Vega, 1989. 